\title{
Mental health is a chain reaction
}

\author{
As the pandemic extends into a third academic year, we must admit that mental health has \\ become a major problem in academia. The responsibility to change academic culture begins \\ at the top.
}

The pandemic has had a serious effect on mental health in academia. Burnout and anxiety have impacted the ability of faculty members to teach, produce research and mentor the next generation. Younger researchers have had their educations disrupted at a critical point in their professional development. With this Editorial, we hope to draw attention to how worsened mental health has affected academics at all stages and emphasize that the consequences of ignoring this problem are both urgent and long-lasting. We publish it in tandem with a Comment by Zoë Ayres that details how research teams can build a supportive culture for better well-being, and ultimately better science.

Faculty are working more hours yet are anxious that they are not doing enough, a feeling exacerbated by the dissolution between home and work boundaries. Pressure to keep research moving and students funded, and learn an entirely new way of teaching, have brought many to a breaking point. In a survey of US faculty in the fall of 2020, over two-thirds of respondents were "extremely" or "very" stressed, compared with less than a third in 2019. Half admitted that their enjoyment of teaching had waned with the move to online learning, many feeling self-doubt and frustration that they were not teaching as effectively as they would like, while devoting substantially more time to it than before.

The consequences of pandemic-era overwork go far beyond stress: faculty are becoming cynical and despondent about their careers, hallmarks of burnout. Of the surveyed faculty, 55\% had felt little or no hope over the past month; only a quarter had felt that way in 2019. An alarming $43 \%$ on the tenure track confessed that they had seriously considered changing careers and leaving higher education altogether since the start of 2020. Astonishingly, so had a third of tenured professors.

Students and junior researchers are also struggling. Many more PhD students are depressed and anxious, according to a survey of more than 15,000 graduate students in the USA conducted in the summer of 2020. Of research doctoral students, $36 \%$ screened positive for symptoms of major depression, double the number from 2019 , and $43 \%$ of this group met the criteria for generalized anxiety disorder, 1.5 times as many as in the previous year. Postdocs' careers have stalled as the pandemic interrupted experiments, curtailed networking and collaborations, and brought visa restrictions and hiring freezes. A majority of postdocs across 93 nations surveyed last summer felt that the pandemic had already negatively affected their professional careers.

As trainees have needed more intensive support during the pandemic, faculty have stepped up, although not necessarily in equal shares. A late-2020 survey of academics, most based in Europe, found that $62 \%$ of female faculty devoted extra time in the pandemic to supervising trainees, leaving less time for primary research activities, compared with $40 \%$ of male faculty. In a poll of US faculty in early 2021, 26\% of female professors said that supporting students in distress had taken a toll on their own mental health. Half as many of their male colleagues $(13 \%)$ reported the same.

The responsibility to improve academic culture and well-being is not faculty's alone. As Ayres recommends, faculty can model healthy behaviour by setting boundaries, taking breaks and being open about their own research setbacks. But faculty need support too. Institutions must invest in faculty mental health assistance, as well as offer or even mandate basic training for faculty to learn how to help students. A report by Cactus Communications, aimed at research institutions and other stakeholders, advocates for key changes to research environments, including anti-bullying and anti-discrimination measures; accountability for poor behaviour of managers and leaders; and fair performance evaluations that consider all aspects of faculty responsibilities, not only publication output.

As we enter the third academic year shaped by COVID-19, we can no longer pretend that this is just something to get through and move on from. The effects of burnout and poor mental health are already cascading down the chain, and they will not be easily reversed. Overworked senior and mid-career academics cannot adequately nurture those in the early stages of their careers, and a year and a half of lost mentorship is a huge chunk of a $\mathrm{PhD}$, a postdoctoral fellowship or a tenure review. Worse, if the most exhausted and overburdened leave higher education altogether, this will be a significant step back for equal representation in academia. Concrete changes can begin to repair the culture; it is time to implement them in earnest. 